\title{
Research on the Characteristics of Officials Corruption in Prefecture-level Cities of China
}

\author{
Liu Yang \\ The School of Government, Central University of Finance and Economics, Beijing, P. R. China \\ Email address: \\ yangliutz@hotmail.com \\ To cite this article: \\ Liu Yang. Research on the Characteristics of Officials Corruption in Prefecture-level Cities of China. International Journal of Economic \\ Behavior and Organization. Vol. 8, No. 4, 2020, pp. 92-100. doi: 10.11648/j.ijebo.20200804.12
}

Received: November 15, 2020; Accepted: December 1, 2020; Published: December 11, 2020

\begin{abstract}
Since the 18th National Congress of the Communist Party of China, while continuously strengthening the institutional system construction of corruption governance and promoting institutional reform, China has also unswervingly carried out the continuous high-pressure anti-corruption practice of "fighting tigers", "shooting flies" and "hunting foxes". In this paper, the secretary of municipal party Committee and mayor in prefecture-level cities are taken as the research objects, and the corruption cases which were publicly reported by the official media after the 18th National Congress of the Communist Party of China (November 2012) are collected, and the relevant indicators are selected to analyze the main characteristics of corruption of officials in prefecture-level cities. The study found that: The corruption of officials in prefecture-level cities is concentrated in four high-risk areas such as engineering, personnel, financial management and land. The average age of first corruption is 41.75 years, and the average incubation period of corruption is 11.43 years. Nearly $80 \%$ of problematic officials in the investigated cases have been promoted. As China's anti-corruption efforts intensify, the age of officials being investigated is getting younger. The interest chain of corruption is complicated, and corruption has contagious effect. Bribery is the most common and main form of corruption. Finally, this paper puts forward the countermeasures and suggestions for the corruption control of the officials in prefecture-level cities under the current situation.
\end{abstract}

Keywords: Corruption, Corruption Characteristics, Incubation Period, Corruption Governance

\section{Introduction}

After more than 40 years of reform and opening up, China has made a series of important achievements in various fields such as economic and social development, but at the same time, corruption has become a severe challenge in the process of China's modernization.

Since the 18th National Congress of the Communist Party of China, the CPC Central Committee has comprehensively promoted the strict administration of the party, strengthened the building of a clean and honest government, resolutely and severely punished corruption, and proposed that anti-corruption should be "no forbidden zone, full coverage, zero tolerance", and constantly strengthen corruption governance. While building the institutional system and promoting institutional reform, it also unswervingly carried out the continuous high-pressure anti-corruption practice of "fighting tigers", "flying flies" and "hunting foxes". According to the official data released by the State
Supervision Committee of the Central Commission for Discipline Inspection, the number of cases filed and the number of persons punished in the whole country are increasing year by year. Since the 19th National Congress, the anti-corruption work has insisted on heavy containment, strong pressure and long shock. In recent years, the cases of officials who have retired for many years have been investigated and reported frequently, which has released a strong signal that China's corruption governance is not relaxed and does not stop.

For China, although the continuous high-pressure anti-corruption since the 18th National Congress of the Communist Party of China has promoted the gradual elimination of corruption stock and the containment of potential corruption to a certain extent, however, corruption is still the biggest social pollution in China, and the governance of corruption is still an important political challenge at present and in the future. It is also necessary to make unremitting efforts to control corruption as a social disease and build a fair 
and clean society. For academic researchers, due to the complexity, concealment and long-term characteristics of corruption, we have not enough understanding and research on the origin, actual occurrence and development of corruption, as well as the characteristics and trends of the spread of corruption, so the research on corruption is also an important academic challenge.

The existing literature at home and abroad studies corruption and corruption governance, mainly from the definition, causes, classification, measurement, influencing factors, development trends, strategy, governance and other dimensions. It involves the intersection and integration of many disciplines such as political science, economics, management, sociology, law, and cultural studies. The World Bank defines corruption as "seeking private interests with public power". Wang Huning (1990) and others put forward earlier that corruption is "the non-public use of public power". Acton, a famous British historian, put forward the classic law of "power leads to corruption, while absolute power absolutely leads to corruption"[1], which reveals the accompanying relationship between power and corruption. Chinese domestic scholars have studied the root causes, characteristics and trends of corruption in China based on the reality of China's economic and social development. $\mathrm{Hu}$ Angang (1994) held that China's corruption at present was mainly caused by institutional corruption, and the occurrence of corruption was mainly rooted in institutional defects in the transition period of market economy [2]. Guo Yong (2007) based on the theory of public choice, analyzed the causes of corruption spread in China during the transition period from three dimensions: corruption motivation, corruption opportunities and institutional constraints, and concluded that economic transition and institutional reform are the main causes of corruption spread in China since the reform and opening up [3]. Tang $\mathrm{N}$ et al. (2018) synthesized a cross-disciplinary literature review of 205 top journals in China from 1989 to 2017, and concluded that human greed, economic transformation, lack of system, fragile civil society and social and cultural traditions were considered as the main reasons for corruption of Chinese public officials [4]. Some scholars pointed out that measuring the actual situation of corruption was the basis of scientifically estimating the impact and consequences of corruption and carrying out corruption control.

From the reality, due to the limited disclosure of information and data related to corruption, the sources of information are scarce, the research on corruption has the characteristics of "secret information asymmetry" and "sensitive information asymmetry". At present, academic circles mainly adopt two kinds of measurement methods: subjective investigation and objective statistics. Some institutions or scholars used a quantitative method to study the corruption level of a country or region through subjective investigation of corruption perception of specific groups. Some scholars made an overall assessment of the corruption situation by statistically analyzing the corruption cases found and punished every year. For example, Wang Chuanli (2001) earlier used the concepts of corruption frequency and the corruption fluctuation cycle of corruption. Based on the number of corruption cases investigated and handled by official agencies from 1988 to 1999 and related conditions, the basic trend of China's corruption frequency in the 1990s was carried out [5]. Ni Xing and Wang Lijing (2003) objectively measured the overall situation of corruption in China by adopting the relevant information of corruption cases investigated and dealt with by official institutions such as discipline inspection and supervision organs, procuratorial organs and judicial organs [6]. Guo Yong (2008) analyzed the characteristics and causes of corruption in China during the transition period by taking 594 major corruption cases published by the government and reported by the media as the research objects [7]. Gong Ting and Wu Muluan (2012) studied 2802 corruption cases reported by Procuratorial Daily from 2000 to 2009, and analyzed the current situation and characteristics of corruption in China with a large sample of official corruption case database. Studies showed that the high-risk groups of corruption were mainly concentrated in the cadres at the bureau level, and the high-incidence cases of corruption were mainly concentrated in the fields of government procurement and project contracting [8]. To sum up, although there are some difficulties in the empirical research on corruption, and the current situation of corruption presented by most literatures is relatively simple and has certain limitations, the empirical research in this field is gradually improving.

The existing literature on the corruption of county-level, prefecture-level, provincial and ministerial level research, although in the case selection object, time period, indicators are different, but all adopt the case statistics method as the main research method, that is, on the basis of integrating and refining the basic information of the case for statistical analysis. Based on the characteristics of concealment and sensitivity of corruption, it is almost impossible to carry out a comprehensive evaluation of corruption. Therefore, it is effective to use the disclosed cases for research, which can show the situation, characteristics and trend of corruption to a certain extent method.

Based on the high-pressure anti-corruption practice of the party and the government since the 18th National Congress of the Communist Party of China, this paper adopts the method of case statistics and analysis, adheres to the principle of "seeking truth from facts", and takes the corruption cases reported by the state media as the research object. This paper attempts to answer the following questions through empirical research: what are the characteristics and trends of corruption of officials in prefecture-level cities? What are the main risk areas? In the future, what measures should be taken to prevent and control the corruption of the officials in prefecture-level cities?

\section{Overview of Case Base}

\subsection{Case Source and Collection Method}

This report collects 105 cases of officials in prefecture-level cities (excluding county-level cities) that have been 
investigated for corruption since the 18th National Congress of the Communist Party of China (November 2012-November 2020). The cases come from the website of the Central Commission for Discipline Inspection and State Supervision Commission, the website of Local Discipline Inspection and Supervision Organs, China Judgment Document Network, People's Daily, China Discipline Inspection and Supervision News, Prosecutorial Daily, People's Daily, Justice Net, Xinhua Network and other official channels. In this paper, the 105 corruption cases of officials in prefecture-level cities are summarized and sorted out, forming three categories of indicators and more than 30 specific indicators, and establishing a corruption case database.

The first category of indicators is the basic information of corrupt officials, including name, gender, ethnicity, date of birth, education level, professional title at the time of investigation, personal resume information, etc. The second category of indicators is the basic information of the cases, including the time of first corruption, the incubation period of corruption, the problems involved, the area where the corruption occurred, the amount of corruption, the time limit for investigation and settlement of the case, the promotion after corruption, the corruption of former and successor officials, etc. The third category is corruption judgment information, including the time of the judgment, the type of disciplinary violation, the type of crime, the term of sentence and the result of the penalty judgment, etc. In the process of sorting out cases, although there are some cases of corruption in which the information published by the official media is missing or incomplete, this paper attempts to use reasonable analysis methods to analyze the limited and accessible information in multiple dimensions, give full play to the maximum efficiency of data, and make the analysis and evaluation results closer to reality.

\subsection{Research Object}

In previous studies, Qiao Defu (2013) studied the corruption cases of the municipal party committee secretary, the mayor, the director of the municipal people's congress, and the chairman of the CPPCC. Liao Chongxu et al. (2017) studied the corruption cases of the municipal party secretary. This article believes that, compared with the director of the Municipal People's Congress and the chairman of the CPPCC, the municipal party committee secretary and mayor, who are responsible for the party and government of a city, occupy a core position in the city's party and government leadership, have greater actual power and it is more direct with the political ecology and economic and social development of the city. Therefore, the case study of official corruption in this article is at the city (prefecture, state, league, and district under the municipality) level, excluding county-level cities, and the research object is the municipal party committee. Secretary, mayor.

\section{Analysis on the Corruption Characteristics of the Officials in Prefecture-level City}

\subsection{Analysis of the Overall Situation of the Case}

\subsubsection{Distribution of the Number of Corruption Cases}

The database contains the number of corruption cases investigated and handled from November 2012 to November 2020. The trend of the number of cases is shown in Figure 1. The highest number of corruption cases occurred in 2014, with 34 cases. The lowest number of corruption cases appeared in 2019, with 4 cases. In the 8 years since the 18th National Congress of the Communist Party of China, the average number of investigations and prosecutions per year has been 13.13. Among them, the number of corruption cases investigated and handled in the four years from 2014 to 2017 was in double digits, and the average number of prosecutions was 20.5, which to a certain extent reflects the strength of China's anti-corruption efforts in recent years.

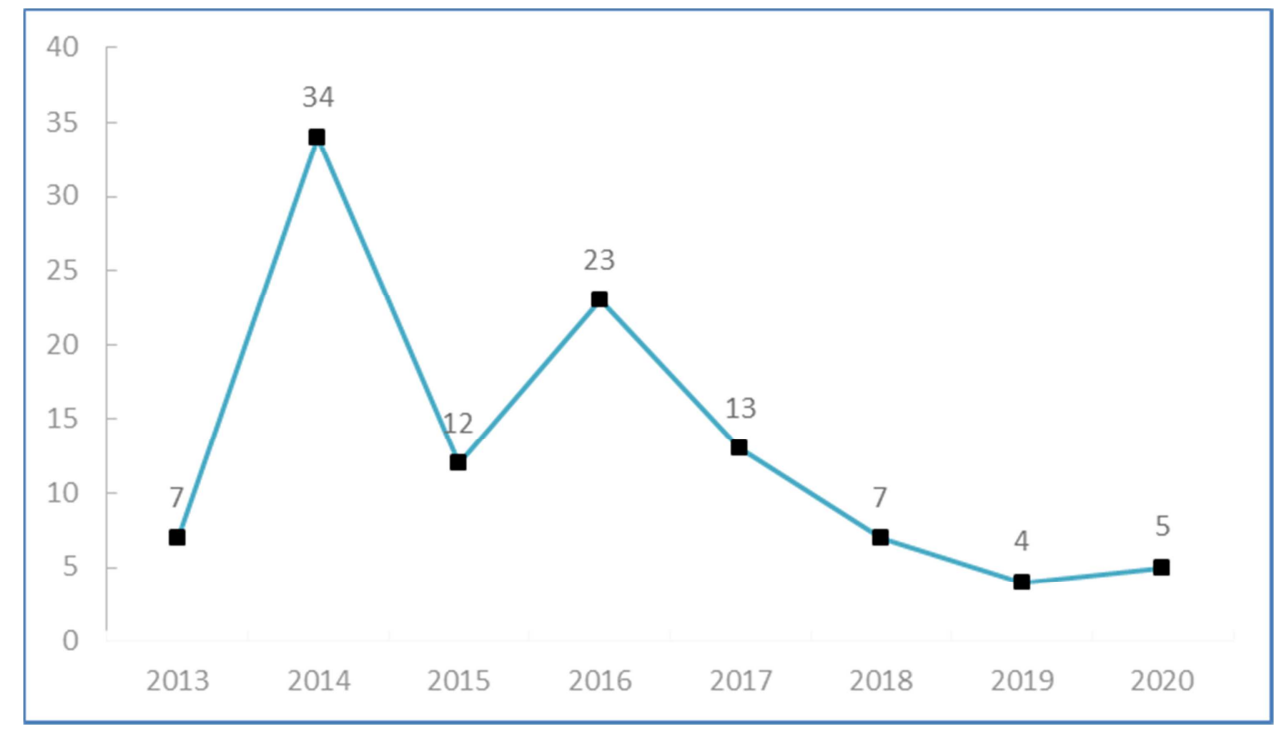

Figure 1. Trend Chart of the Number of Corruption Cases of officials in Prefecture-level Cities of China. 


\subsubsection{The Geographical Distribution of Corruption Cases}

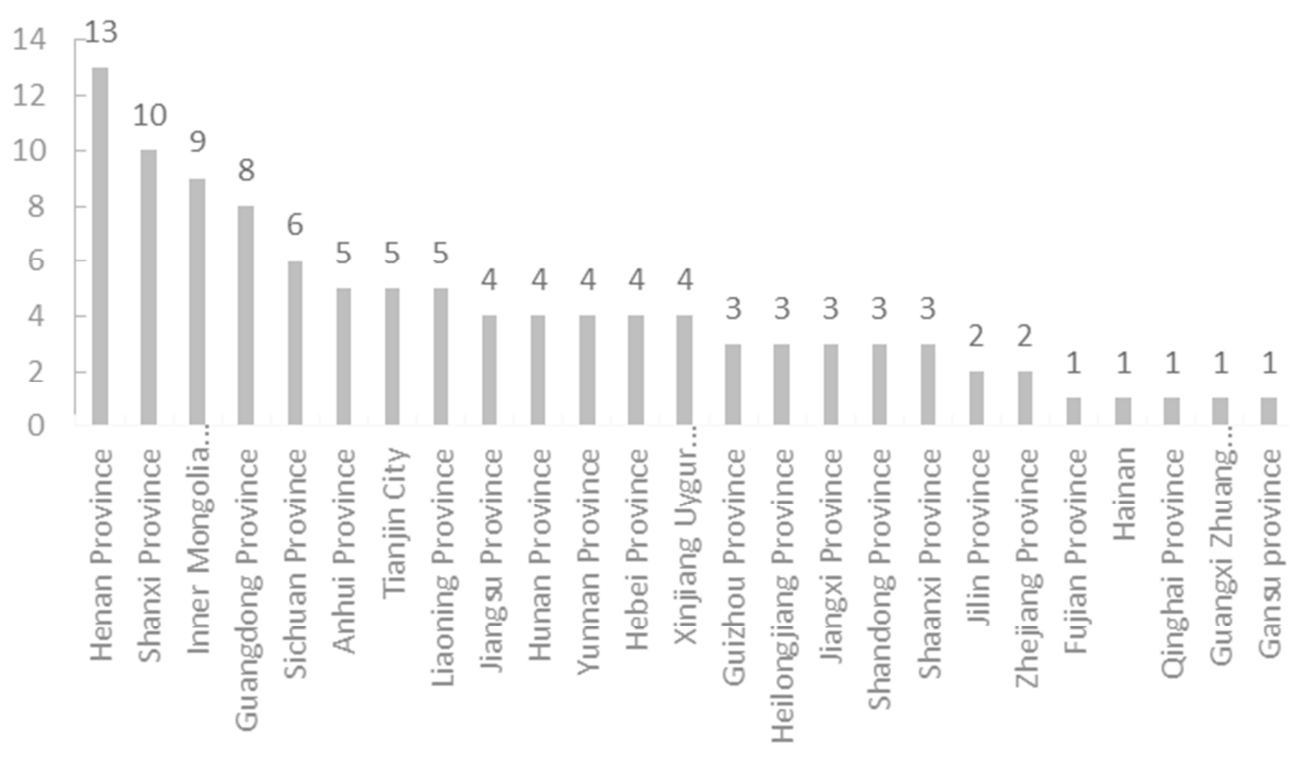

Source: Author's database.

Figure 2. Geographical Distribution Map of Corruption Cases of officials in Prefecture-level Cities of China.

Among the 32 provincial-level administrative regions (excluding the 2 special administrative regions), 25 provincial-level administrative regions have prefecture-level city municipal party committee secretaries and mayors investigated, accounting for $78.13 \%$. The top three provinces in terms of the number of cases are: Henan Province 13 cases, Shanxi Province 10 cases, and Inner Mongolia Autonomous Region 9 cases. The geographical distribution is shown in Figure 2. Provinces with a large number of corruption cases, such as the systematic and collapse corruption in some cities in Shanxi Province, and the three-term party secretary of Sanmenxia City, Henan Province corrupted and fell in succession, etc. Among the provincial-level administrative regions, 18 of the corruption officials of prefecture-level cities were located in provincial capitals at the time of investigation, and the remaining 87 were non-provincial capitals.

\subsubsection{Position Distribution of Officials at the Time of Investigation}

Among the 105 corrupt prefecture-level city officials, 79 were the secretary of the municipal party committee and 28 were the mayor.

As shown in Table 1, at the time of investigation, there were 26 officials at the vice-provincial level (15 of them were promoted to the Standing Committee of the Provincial Party Committee, 5 were promoted to the Vice Governor, 3 were promoted to the Deputy Secretary of the Party Group of the Standing Committee of the Provincial People's Congress, 2 were promoted to the member of the Provincial Government party group, 1 was promoted to vice chairman of the Provincial Committee of the Chinese People's Political Consultative Conference), bureau-level officials were 72 , and there were 7 retired officials.

It is worth noting that in the three years from 2018 to 2020 , seven retired Chinese officials have been investigated and punished, which reflects the determination and strength of China's anti-corruption work to a certain extent. With the in-depth promotion of China's anti-corruption work, retirement does not mean that the past latent corruption acts can be exempted from extra-legal, and retirement does not mean "landing safely".

Table 1. Position Statistics of Corrupt Officials in China at the Time of Investigation.

\begin{tabular}{lllll}
\hline \multirow{2}{*}{$\begin{array}{l}\text { Position level at the time of } \\
\text { investigation }\end{array}$} & \multicolumn{2}{l}{ Vice-provincial level } \\
\cline { 2 - 5 } & Subtotal & $\begin{array}{l}\text { Provincial Party Committee } \\
\text { Standing Committee }\end{array}$ & $\begin{array}{l}\text { Vice } \\
\text { governor }\end{array}$ & $\begin{array}{l}\text { Deputy Secretary of the Party Group of the Standing } \\
\text { Committee of the Provincial People's Congress }\end{array}$ \\
\hline $\begin{array}{l}\text { Number of corrupt officials } \\
\text { Proportion of the total }\end{array}$ & 26 & 15 & 5 & 3 \\
\hline
\end{tabular}

Table 1. Continued.

\begin{tabular}{llll}
\hline \multirow{2}{*}{$\begin{array}{l}\text { Position level at the time of } \\
\text { investigation }\end{array}$} & \begin{tabular}{l} 
Vice-provincial level \\
\cline { 2 - 3 }
\end{tabular} & $\begin{array}{l}\text { Member of the provincial government } \\
\text { party group }\end{array}$ & $\begin{array}{l}\text { Vice Chairman of the Provincial } \\
\text { CPPCC }\end{array}$ \\
\hline $\begin{array}{l}\text { Number of corrupt officials } \\
\text { Proportion of the total }\end{array}$ & 2 & 1 & 72 \\
\hline
\end{tabular}

Source: Author's database. 


\subsubsection{Cross-regional Appointments of Corrupt Officials}

Database case statistics show that among the 68 officials who have published detailed information on the process of corruption, $57(83.83 \%)$ had cross regional corruption, that is, the city where corruption first occurred was different from the city where corruption was investigated. Existing studies have found that official exchanges and tenure restrictions have a positive effect on the suppression of corruption. In contrast, in this paper, the proportion of corrupt officials in cross regional communication is much higher than that in non cross regional communication.

\subsection{Analysis of the Characteristics of Corrupt Officials in Prefecture-level Cities}

\subsubsection{Male and Han Officials Account for a High Proportion}

Among the 105 officials investigated, there are 101 male officials and 4 female officials. There are 102 Han officials and 3 ethnic minority officials, including 1 Mongolian, 1 Uyghur and 1 Yao.

In existing studies, some scholars have suggested that compared with male officials, female officials have a lower tolerance for corruption, and government agencies with a high proportion of female officials have a lower degree of corruption. Some scholars also pointed out that there is no direct relationship between gender and corruption. This paper argues that the high proportion of males among senior Chinese officials is the result of various comprehensive factors such as politics, society and culture, and whether there is correlation between corruption and gender needs further study.

\subsubsection{Highly Educated}

As shown in Table 2, Among the 105 corrupt officials, the level of education is as follows: 1 junior college degree holders, 14 bachelor degree holders, 67 masters degree holders, and 23 doctoral degree holders.

There are 61 officials choose to pursue advanced education on-the-job, accounting for nearly $60 \%$. Among them, there are 2 officials who have been promoted from junior college degree to undergraduate degree, 36 officials who have been promoted from undergraduate degree to master degree, and 23 officials who have been promoted from master degree to doctoral degree. It is particularly noteworthy that among the 26 deputy provincial officials, 11 chose to pursue their doctoral studies and 12 chose to pursue their master's degrees. The selection and appointment of cadres in China in recent years has shown a trend of higher education and younger age. The situation reflected in this case database is also consistent with this trend.

Table 2. Educational Background of Corrupt Officials in Prefecture-level Cities of China

\begin{tabular}{lllll}
\hline Year & $\begin{array}{l}\text { Junior } \\
\text { college }\end{array}$ & $\begin{array}{l}\text { Bachelor } \\
\text { degree }\end{array}$ & $\begin{array}{l}\text { Master's } \\
\text { degree }\end{array}$ & $\begin{array}{l}\text { Doctoral } \\
\text { degree }\end{array}$ \\
\hline 2013 & 0 & 1 & 4 & 2 \\
2014 & 1 & 8 & 18 & 7 \\
2015 & 0 & 0 & 9 & 3 \\
2016 & 0 & 2 & 15 & 6 \\
2017 & 0 & 1 & 10 & 2 \\
\hline
\end{tabular}

\begin{tabular}{lllll}
\hline Year & $\begin{array}{l}\text { Junior } \\
\text { college }\end{array}$ & $\begin{array}{l}\text { Bachelor } \\
\text { degree }\end{array}$ & $\begin{array}{l}\text { Master's } \\
\text { degree }\end{array}$ & $\begin{array}{l}\text { Doctoral } \\
\text { degree }\end{array}$ \\
\hline 2018 & 0 & 1 & 4 & 2 \\
2019 & 0 & 1 & 3 & 0 \\
2020 & 0 & 0 & 4 & 1 \\
Total & 1 & 14 & 67 & 23 \\
\hline
\end{tabular}

Source: Author's database.

\subsection{Analysis on the Characteristics of Corruption Cases of Officials in Prefecture-level City}

\subsubsection{Engineering, Personnel, Financial Management and Land Are the Four High-risk Areas of Corruption}

The 105 case information collected in this database shows that engineering, personnel, financial management and land, are the four major areas with high risks of corruption. Among them, As shown in Figure 3, contracting projects, cadre selection, job promotion and adjustment, business operations, and special funds Appropriation, real estate development, land transfer, etc. are the most prone and serious corruption issues.

The New Public Management Movement advocated the socialization of public services and promoted the widespread adoption of "agent administration". A large number of services previously provided by the government were transferred to the third sector, which played an important role in coordinating resources and improving work efficiency. But at the same time, there are some shortcomings in the socialization of public services. For example, due to the lack of regulations and the insufficient control and supervision, the risk of corruption in this area will increase. The database in this article shows that contracting projects is the most prone to corruption, which has also been confirmed.

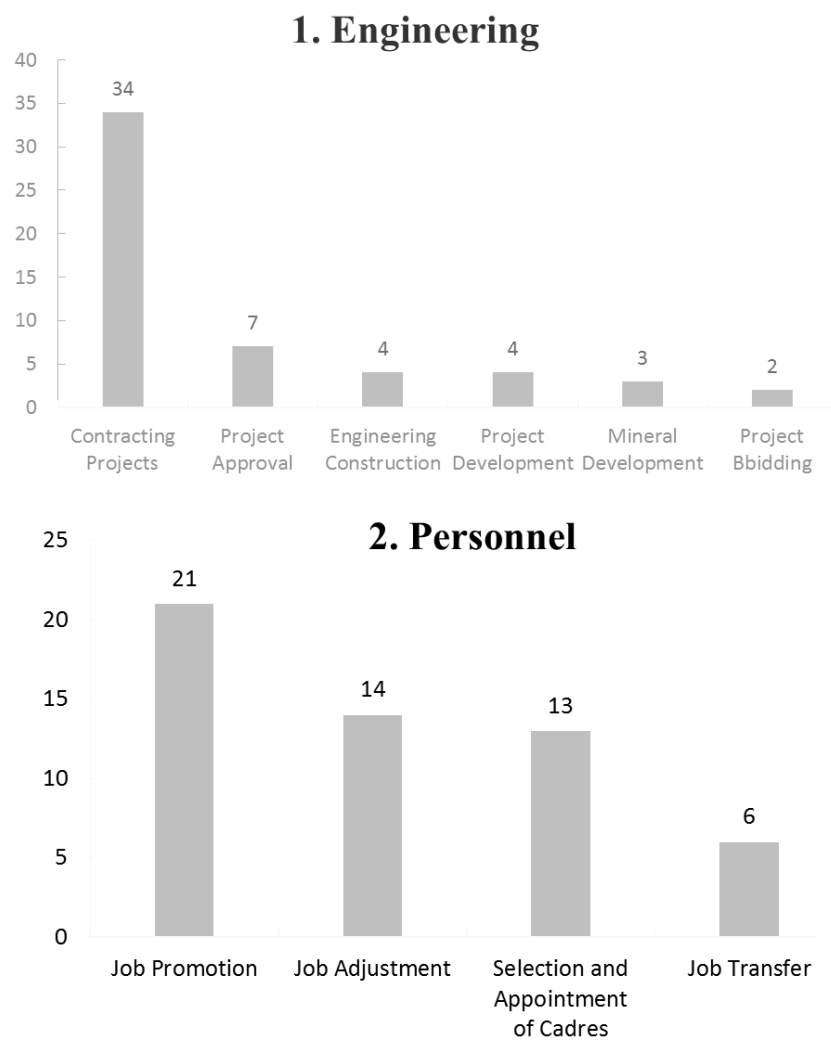




\section{Financial Management}

25

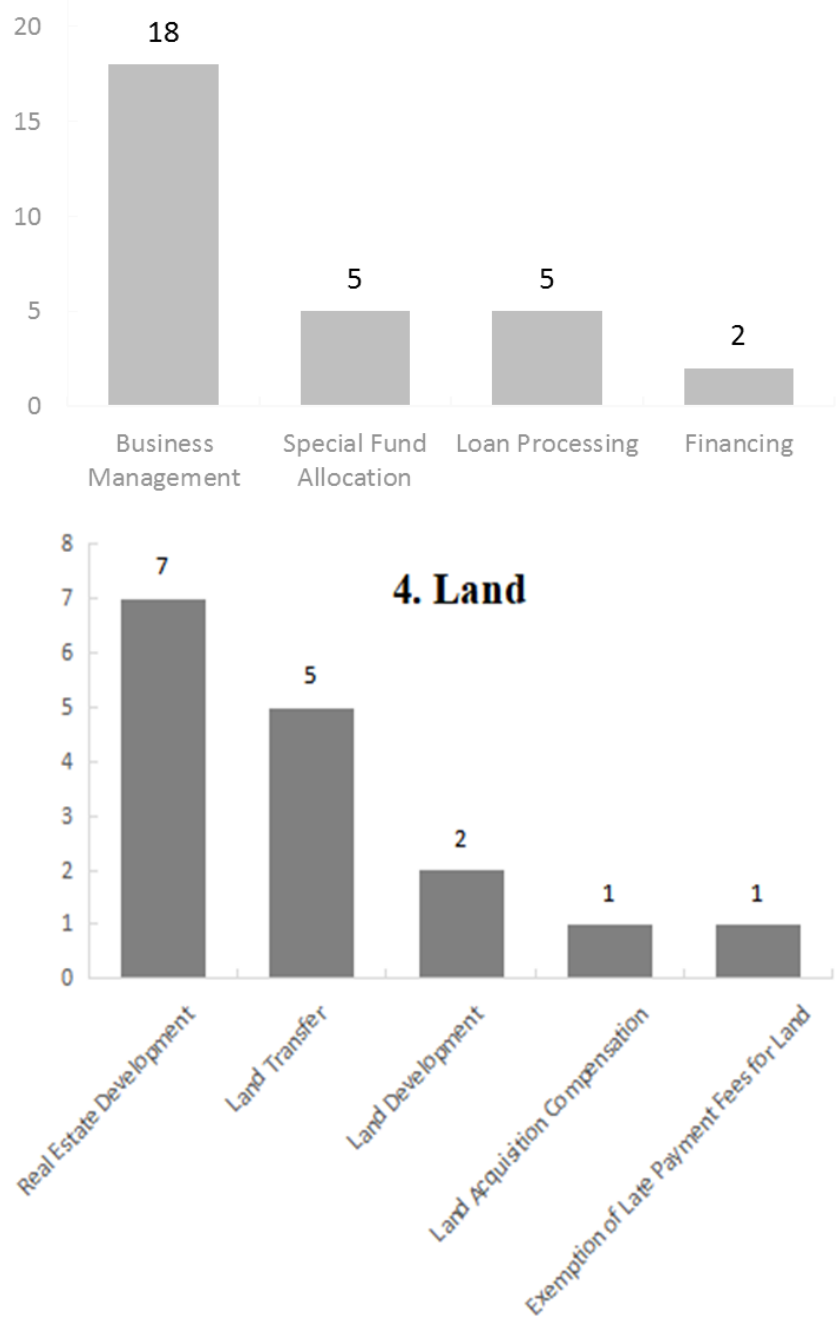

Source: Author's database.

Figure 3. Distribution of High-risk Areas of Corruption Among the Officials in Prefecture-level Cities of China.

\subsubsection{Long Latent Period of Corruption}

The latent period of corruption refers to the time span from the first corruption of an official to the investigation of the corruption. The database shows that officials in prefecture-level cities investigated after the 18th National
Congress of the Communist Party of China had the longest latent period for corruption of 22 years, the shortest latent period was one year, and the average corruption latent period was 11.43 years (as shown in Figure 4). The longest latent period and average latent period of corruption all show an inverted U-shaped trend.

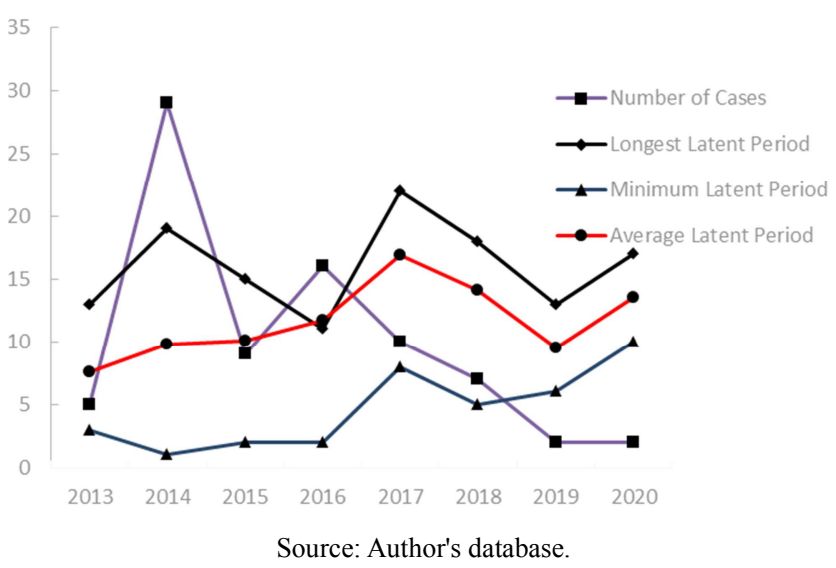

Figure 4. Distribution of The Latent Period of Officials Corruption Cases in Prefecture-level Cities of China.

Among the 105 corruption cases of officials in prefecture-level cities, 80 have publicly reported the process of corruption in detail. Among them, the oldest was 56 years old at first corruption; the youngest was 28 years old, and the average age at first corruption was 41.75 years old. Among them, the youngest person to accept bribes for the first time was Zhou Chunyu, the former deputy governor of Anhui Province and former secretary of the Bengbu Municipal Party Committee. He had been corrupt as early as 1996 when he served as deputy secretary of the General Office of the Anhui Provincial Party Committee. During the 23-year corruption incubation period, his involvement in the case of bribery, abuse of power, and insider trading exceeded 1 billion yuan.

As shown in Table 3, according to the database, when the officials first became corrupt, they were 1 at the deputy provincial level, 23 at the bureau level, 29 at the deputy bureau level, 20 at the department level, 6 at the deputy department level, and 1 section chieft.

Table 3. The Administrative Level of Initial Corruption of Officials in Prefecture-level Cities of China.

\begin{tabular}{|c|c|c|c|c|c|c|}
\hline $\begin{array}{l}\text { Administrative } \\
\text { Level }\end{array}$ & $\begin{array}{l}\text { Deputy Provincial } \\
\text { Level }\end{array}$ & Bureau Level & $\begin{array}{l}\text { Deputy Bureau } \\
\text { Level }\end{array}$ & Department Level & $\begin{array}{l}\text { Deputy } \\
\text { Department Level }\end{array}$ & $\begin{array}{l}\text { Section Chieft } \\
\text { Level }\end{array}$ \\
\hline Number of people & 1 & 23 & 29 & 20 & 6 & 1 \\
\hline Percentage of total & $1.25 \%$ & $28.75 \%$ & $36.25 \%$ & $25.00 \%$ & $7.50 \%$ & $1.25 \%$ \\
\hline
\end{tabular}

Source: Author's database.

This study found that $65 \%$ of officials' initial corruption mainly started at the bureau level. The author believes that good career development expectations can give officials a certain incentive. For officials who lack incentives, officials who receive more incentives have stronger self-discipline and weaker motives for corruption.

\subsubsection{The Phenomenon of Promoting Problematic Officials}

Combined with the above research on the latent period of corruption, another finding of this study is that, among the officials investigated, nearly $80 \%$ of problematic officials in 
prefecture-level cities had been promoted.

As shown in Table 4, among the problematic officials who were promoted, $36.71 \%$ were promoted to one level, $31.65 \%$ were promoted to two levels, $7.59 \%$ were promoted to three levels, and $3.80 \%$ were promoted to four levels. Those who were promoted to one and two levels accounted for $85.71 \%$ of the total number of promotion.

Table 4. Status of Promotion of Problematic Officials in Prefecture-level Cities of China.

\begin{tabular}{llllll}
\hline promote problematic officials & Total & One Level & Two Levels & Three Levels & Four Levels \\
\hline Number of People & 63 & 29 & 25 & 3 & $7.59 \%$ \\
Percentage of Total & $79.75 \%$ & $36.71 \%$ & $31.65 \%$ & $3.80 \%$ & $7.59 \%$ \\
\hline
\end{tabular}

Source: Author's database.

As shown in figure 5, when the corruption case was investigated, the youngest official was 43 years old, the oldest was 68 years old, and the average age of the officials was 55 years old. Previous studies by scholars have shown that there is a "58-year-old phenomenon" in the corruption of Chinese officials, that is, officials are prone to corruption at the age of 58 when they are about to retire. This study finds that with the increase in anti-corruption efforts, the age at which corruption is investigated is showing a younger trend.

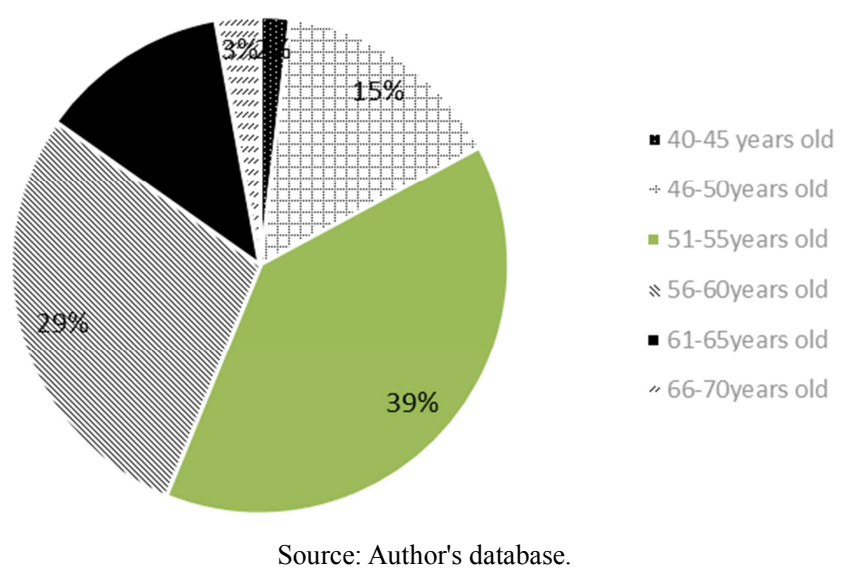

Figure 5. Age distribution of Officials in Prefecture-level Cities of China.

As shown in figure 6, when the corruption was investigated, there were 71 officials aged 51-60, accounting for $67.62 \%$ of the total number. Among them, there were 41 people aged $51-55$, accounting for $39.05 \%$ of the total number.

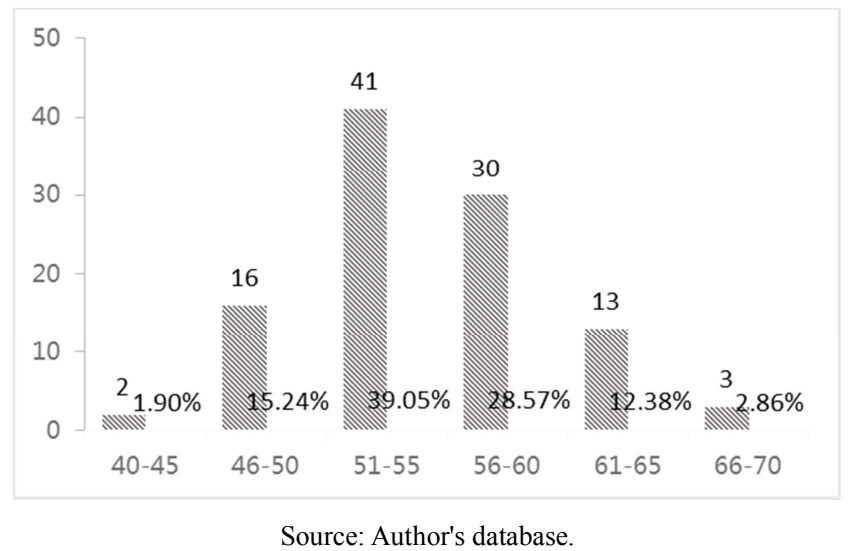

Figure 6. Age Distribution and Number of Corruption Cases of officials in Prefecture-level Cities of China.

\subsubsection{The Profit Chain of Corruption Is Complex, and Corruption Has Contagious Effects}

Some scholars have shown that since China's reform and opening up (1978), China's corruption crimes have shown a trend of "from corruption and misappropriation to bribery and acceptance, then to conflict of interest" [11]. Officials and businessmen, gangs, and family members colluded with improper or illegal interests, thus establishing a chain of corrupt interests.

Through the statistical analysis of cases, this paper finds that the corruption of officials in prefecture-level cities is not individual corruption, and there are often a group or a series of stakeholders behind it. According to the case database, collusion between officials and businessmen, trade in power and money, form cliques, family members participated in corruption and using officials influence to commit crimes are all common corruption phenomena.

Corruption cases are usually interspersed with corruption interest chains. The "hunting" of officials by bribers often includes the "hunting" of officials' social networks [12]. The officials who are "hunted" and the stakeholders have established their own interests relationship, or for power trading, power money trading, power-pornography trading, etc., thus forming an intricate, explicit or implicit corruption interest chain, and corruption has shown a trend of institutionalization and socialization.

The intricate chain of corruption has caused great damage to the political ecology. Previous studies have shown that corruption of senior officials has a significant demonstration (contagion) effect on other officials [13]. The corruption of senior officials often leads to the deterioration of the atmosphere of a region and a group, and can easily promote the corruption motivation of low and middle-level officials, which can be described as "the upper beam is not right, and the bottom beam is crooked". The large number of collective corruption and cascading cases in the case database also reflect and verify the demonstration (contagion) effect of corruption to a certain extent.

\subsubsection{Bribery Crime Is the Main Type of Corruption Crime}

As shown in figure 7, among the officials corruption cases in 105 prefecture-level cities, 98 cases have been pronounced and convicted, of which 97 were convicted of accepting bribes and 1 was convicted of negligence; Five others have not reported specific charges, and two are under investigation. 


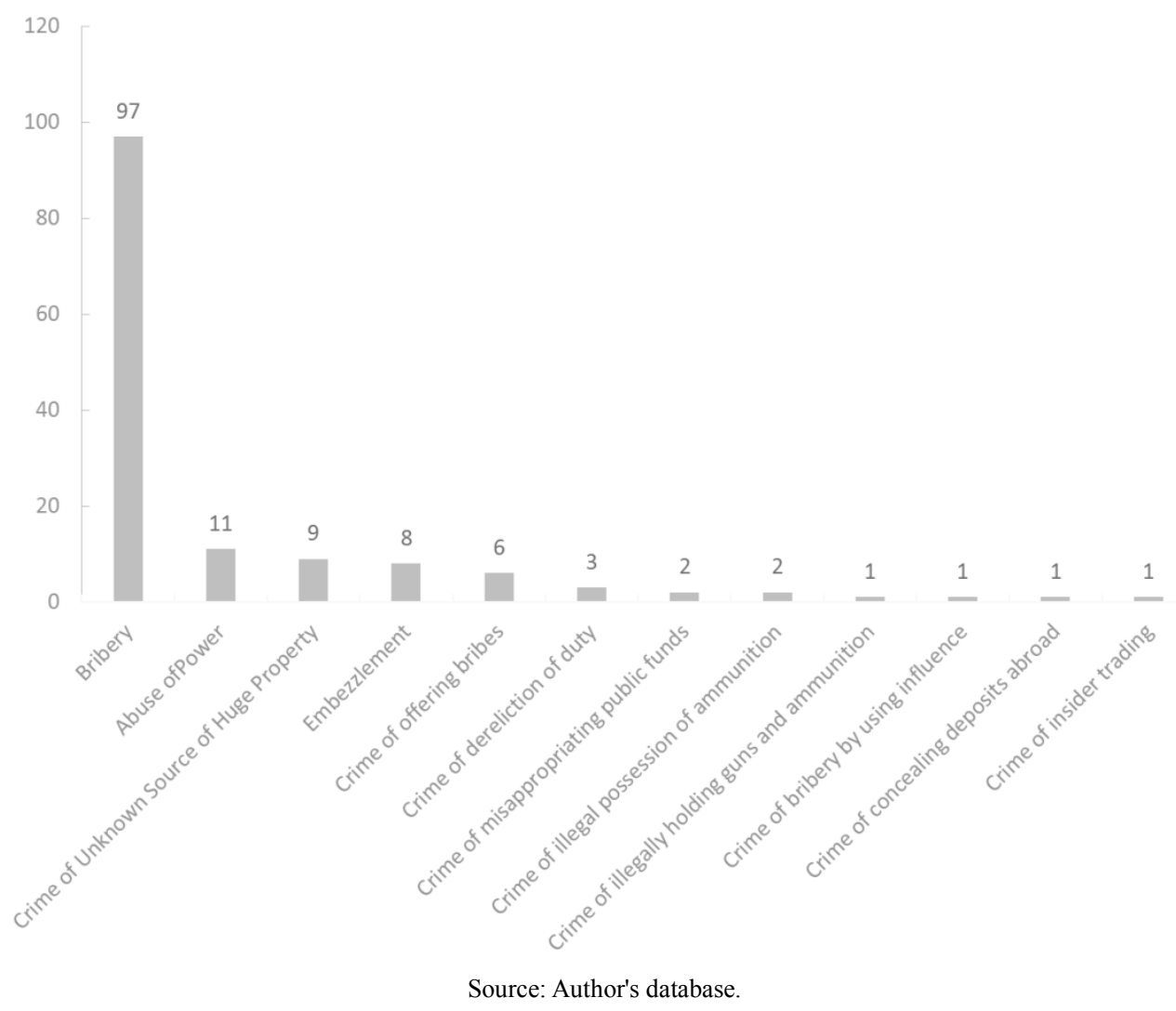

Figure 7. Distribution of Cases Involved by Officials in Prefecture Level Cities of China.

As shown in figure 8, in terms of sentencing, there were 2 people with a sentence of less than 5 years, 6 people with a term of 6-10 years, 40 people with a term of 11-15 years, and 9 people with sentences of 16-20 years. 9 people were sentenced to life imprisonment and 1 is sentenced to death. Among them, the prison term of $11-15$ years is relatively concentrated, accounting for nearly $60 \%$. In accordance with the relevant provisions of the criminal law on sentencing, this proportion to a certain extent also reflects that there are a considerable number of officials taking bribes, the amount of which is particularly huge, or there are relatively serious criminal circumstances.

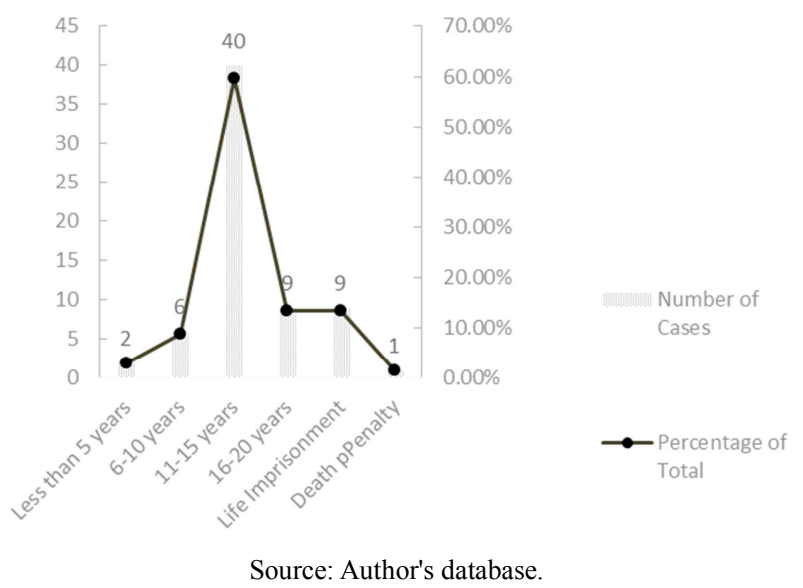

Figure 8. Distribution of Sentences in Corruption Cases of Officials in Prefecture Level Cities of China.

\section{Conclusion and Suggestions}

\subsection{The Main Conclusion}

Based on the empirical analysis of the cases of corrupt officials in prefecture-level cities which were publicly reported by Chinese official media, this paper draws the following conclusions:

1. More than $96 \%$ of the corrupt officials in prefecture-level cities are male and Han.

2. Corrupt officials in prefecture-level cities are highly educated, and nearly $60 \%$ of officials choose to pursue advanced education on-the-job.

3. Engineering, personnel, financial management and land are the four high-risk areas of corruption among officials in prefecture-level cities.

4. The latent period of corruption is long, the amount involved is large, and the geographical coverage is wide. The average age of first corruption is 41.75 years old, and the average incubation period of corruption is 11.43 years, and the investigation after retirement shows an increasing trend. $65 \%$ of officials'initial corruption mainly started at the bureau level.

5. The problem of promoting problematic officials is outstanding. Nearly $80 \%$ of problematic officials have been promoted. Those who were promoted to one and two levels accounted for $85.71 \%$ of the total number of promotion.

6. Compared with the "58-year-old phenomenon" in the corruption of Chinese officials, with the increase of 
anti-corruption, the age at which corruption is investigated is showing a younger trend.

7. The profit chain of corruption is complex, and corruption has contagious effects.

8. Bribery crime is the most common and main form of corruption crime.

\subsection{Research Inspiration}

Generally speaking, since the 18 th National Congress of the Communist Party of China, the intensity of China's anti-corruption has increased significantly [14]. The above conclusions show that the current corruption governance situation in China is still severe. This paper believes that the municipal party committee secretaries and mayors of prefecture-level cities play the role of planning, organization, command, coordination, and control in the leadership team. They often hold greater powers, have a more obvious right to speak, and have a greater impact on decision-making. The excessive concentration of power and excessive discretion objectively form their absolute authority, the operation of power was not open and transparent, and the supervision and supervision mechanism of power was not perfect, etc., which provided motivation and opportunity for the corruption. This paper argues that these are the main reasons that lead to the corruption of the officials in prefecture-level cities.

In-depth analysis of corruption, finding out the root causes of corruption, using strategic management methods, focusing on how to curb the occurrence of future corruption and how to strengthen the handling of future corruption, and integrate the prevention, control and punishment strategies of corruption throughout the entire process of corruption governance. Reform the officials power allocation method, standardize administrative power, optimize the power structure, operating mechanism and restraint mechanism, and strive to build a working mechanism that "does not dare to be corrupt", "cannot be corrupt" and "do not want to be corrupt". At the same time, it is necessary to strengthen the supervision of party committees and officials by discipline inspection and supervision agencies, and explore effective measures for multiple subjects to participate in corruption supervision, provide a more convenient, effective and safe channel for public reporting, and transform the public's anti-corruption intentions into actual actions [15]. Establish a trinity power supervision performance evaluation system for corruption prevention, punishment and control.

\subsection{Research Limitations}

Due to the hidden and sensitive nature of corruption, the case library established in this paper only covers the corruption of officials in prefecture-level cities that have been investigated since the 18th National Congress of the Communist Party of China. This is just a part of China's corruption cases in transition. In addition, some publicly reported case information is incomplete, which may lead to the limitation of statistical characteristics and results of this case. These problems will be improved in the future research.

\section{References}

[1] Acton, John Emerich Edward Dalberg Acton, Baron, Himmelfarb, Gertrude. Essays on freedom and power [M]. World Pub. Co. 1955.

[2] Hu Angang, Kang Xiaoguang. Eradicating corruption through institutional innovation [J]. Reform and theory, 1994 (03): 3-8.

[3] Guo Yong. Economic transition, system and corruption [M]. Social Sciences Literature Press, 2007.

[4] Tang N, Ding Z, Xu Y. Corruption and Anti-Corruption Research in China: A Critical Review of Chinese Top Journal Publications (1989-2017) [J]. Chinese Public Administration Review, 2018, 9 (2): 79.

[5] Wang Chuanli. Analysis of corruption frequency in Chinese society from 1990 to 1999 [J]. Political science research, 2001, 000 (001): 38-55.

[6] Ni Xing, Wang Lijing. Measurement of corruption status and estimation of corruption consequences in China [J]. Jianghan forum, 2003, 000 (010): 18-21.

[7] Guo Yong. An Empirical Study on the characteristics and trends of corruption in China's transition period [J]. Public management review, 2008 (No. 1): 63-77.

[8] Gong Ting, Wu muluan. Research Report on corruption cases in China from 2000 to 2009 -- Based on the analysis of more than 2800 reported cases [J]. Sociological research, $2012(04)$ : 204-220.

[9] Qiao Defu. Research Report on corruption cases of "top leaders" in prefecture level cities since reform and opening up -- Based on the analysis of corruption cases of "top leaders" in 142 prefecture level cities [J]. Theory and reform, 2013 (05): 65-71.

[10] Liao Chongxu, Li houqiang, Zhou Dong. Research on the influence of local "top leaders" corruption: An Empirical Analysis Based on the Secretary of Luoma municipal Party committee after the 18th CPC National Congress [J]. Social science research, 2017 (01): 51-59.

[11] Guo Yong. Six development trends of current corruption and anti-corruption in China [J]. Chinese Administration, 2013, 01: 60-63.

[12] Peng Xiaobing, Zeng Baodie. Power hunting ground: How to build a network of corruption relations - Research on bribery path and corruption governance based on motivation theory [J]. Theory and Reform, 2020 (03): 47-59.

[13] Chen Gang. Upper and lower effects: A Study on the demonstration effect of senior officials' corruption [J]. Comparison of economic and social systems, 2013 (02): 155-164.

[14] Guo Yong. The situation of corruption after the 18th National Congress of the Communist Party of China: Evaluation of Three Dimensions [J]. Political Science Research, 2017 (03): $2-11+125$.

[15] Ni Xing, Zhang Jun. Cultural environment, anti-corruption performance, institutional arrangements, and public anti-corruption willingness: An analysis based on the 2016 National Integrity Survey Data [J]. Henan Social Sciences, 2017, 25 (05): 8-15+29. 